\title{
A novel technique for non-volitional assessment of quadriceps muscle endurance in humans
}

Citation for published version (APA):

Swallow, E. B., Gosker, H. R., Ward, K. A., Moore, A. J., Dayer, M. J., Hopkinson, N. S., Schols, A. M., Moxham, J., \& Polkey, M. I. (2007). A novel technique for non-volitional assessment of quadriceps muscle endurance in humans. Journal of Applied Physiology, 103(3), 739-746.

https://doi.org/10.1152/japplphysiol.00025.2007

Document status and date:

Published: 01/01/2007

DOI:

10.1152/japplphysiol.00025.2007

Document Version:

Publisher's PDF, also known as Version of record

Document license:

Taverne

Please check the document version of this publication:

- A submitted manuscript is the version of the article upon submission and before peer-review. There can be important differences between the submitted version and the official published version of record.

People interested in the research are advised to contact the author for the final version of the publication, or visit the DOI to the publisher's website.

- The final author version and the galley proof are versions of the publication after peer review.

- The final published version features the final layout of the paper including the volume, issue and page numbers.

Link to publication

\footnotetext{
General rights rights.

- You may freely distribute the URL identifying the publication in the public portal. please follow below link for the End User Agreement:

www.umlib.nl/taverne-license

Take down policy

If you believe that this document breaches copyright please contact us at:

repository@maastrichtuniversity.nl

providing details and we will investigate your claim.
}

Copyright and moral rights for the publications made accessible in the public portal are retained by the authors and/or other copyright owners and it is a condition of accessing publications that users recognise and abide by the legal requirements associated with these

- Users may download and print one copy of any publication from the public portal for the purpose of private study or research.

- You may not further distribute the material or use it for any profit-making activity or commercial gain

If the publication is distributed under the terms of Article $25 \mathrm{fa}$ of the Dutch Copyright Act, indicated by the "Taverne" license above, 


\title{
A novel technique for nonvolitional assessment of quadriceps muscle
}

\section{endurance in humans}

\author{
E. B. Swallow, ${ }^{1}$ H. R. Gosker, ${ }^{2}$ K. A. Ward, ${ }^{2}$ A. J. Moore, ${ }^{1}$ M. J. Dayer, ${ }^{1}$ N. S. Hopkinson, ${ }^{1}$ \\ A. M. W. J. Schols, ${ }^{2}$ J. Moxham, ${ }^{3}$ and M. I. Polkey ${ }^{1}$ \\ ${ }^{1}$ Respiratory Muscle Laboratory, Royal Brompton Hospital, London, United Kingdom; ${ }^{2}$ Department of Respiratory Medicine, \\ University of Maastricht, Maastricht, The Netherlands; and ${ }^{3}$ Respiratory Muscle Laboratory, King's College London School \\ of Medicine, London, United Kingdom
}

Submitted 6 January 2007; accepted in final form 5 June 2007

\begin{abstract}
Swallow EB, Gosker HR, Ward KA, Moore AJ, Dayer MJ, Hopkinson NS, Schols AM, Moxham J, Polkey MI. A novel technique for nonvolitional assessment of quadriceps muscle endurance in humans. J Appl Physiol 103: 739-746, 2007. First published June 14, 2007; doi:10.1152/japplphysiol.00025.2007.—Assessment of quadriceps endurance is of interest to investigators studying human disease. We hypothesized that repetitive magnetic stimulation (rMS) of the intramuscular branches of the femoral nerve could be used to induce and quantify quadriceps endurance. To test this hypothesis, we used a novel stimulating coil to compare the quadriceps endurance properties in eight normal humans and, to confirm that the technique could be used in clinical practice, in eight patients with advanced chronic obstructive pulmonary disease (COPD). To validate the method, we compared in vivo contractile properties of the quadriceps muscle with the fiber-type composition and oxidative enzyme capacity. We used a Magstim Rapid $^{2}$ magnetic nerve stimulator with the coil wrapped around the quadriceps. Stimuli were given at $30 \mathrm{~Hz}$, a duty cycle of 0.4 ( $2 \mathrm{~s}$ on, $3 \mathrm{~s}$ off), and for 50 trains. Force generation and the surface electromyogram were measured throughout. Quadriceps twitch force, elicited by supramaximal magnetic stimulation of the femoral nerve, was measured before and after the protocol. Quadriceps muscle biopsies were analyzed for oxidative (citrate synthase, CS) and glycolytic (phosphofructokinase, PFK) enzyme activity and myosin heavy chain isoform protein expression. The time for force to fall to $70 \%$ of baseline $\left(\mathrm{T}_{70}\right)$ was shorter in the COPD group than the control group: $55.6 \pm 26.0$ vs. $121 \pm 38.7 \mathrm{~s}(P=$ 0.0014). Considering patients and controls together, positive correlations were observed between $\mathrm{T}_{70}$ and the proportion of type I fibers $(r=0.68, P=0.004)$ and CS-to-PFK ratio (CS/PFK) $(r=0.67, P=$ $0.005)$. We conclude that quadriceps endurance assessed using rMS is feasible in clinical studies.
\end{abstract}

skeletal muscle fatigue; magnetic stimulation; myosin heavy chains; oxidative capacity

QUADRICEPS WEAKNESS, usually expressed as a function of body weight, is increasingly recognized as a marker of morbidity and mortality in a variety of conditions, including chronic obstructive pulmonary disease (COPD) (34) and congestive cardiac failure (16), and indeed in unselected elderly humans in general (24). Some emerging therapies are aimed at improving quadriceps function (10), and so accurate assessment of quadriceps contractility is likely to be useful to investigators studying human disease in vivo. We previously described the technique of supramaximal magnetic stimulation of the femoral nerve (30) and showed that it could be used to study patients

Address for reprint requests and other correspondence: E. B. Swallow, Respiratory Muscle Laboratory, Royal Brompton Hospital, Fulham Rd., London SW3 6NP, United Kingdom (e-mail: libbyswallow@gmail.com). with serious medical conditions, including COPD (29) and stroke (15). However, while this technique has the advantage that the data obtained are independent of patient aptitude or motivation, it offers no information regarding the endurance properties of the muscle.

Endurance is a different quality from strength; while recent guidelines (3) recognize that endurance and strength are sometimes linked, many examples exist where this is not so. Current methods used to assess quadriceps endurance require the subject to make repeated quadriceps contractions, and it is assumed that patients are able to achieve maximal efforts (or make sequential efforts of equal intensity) $(1,8,11,20,33)$. However, central drive to contracting peripheral muscle can be influenced by exercise $(9,36)$ or hypoxia $(38)$, which would influence measured endurance. In addition, it is likely that patients with serious medical illness would fail to generate sequential maximal efforts; indeed, where this has been explored using twitch interpolation, investigators have found it consistently difficult to ensure efforts are truly maximal even in healthy humans (2). Even when maximal activation is ensured, it is known that neuronal discharge frequency reduces progressively during a voluntary effort (6) so that the measured force is a result both of rate and recruitment patterns quite apart from intrinsic properties of the muscle.

In contrast, the intrinsic endurance properties of a muscle can be assessed by the rate at which tension generation declines during repeated nerve stimulation. Repetitive stimuli at high intensity given to the femoral nerve in the femoral triangle are, in our experience, painful, and it is difficult to preserve constancy of stimulation because of movement of the coil relative to the nerve. We therefore designed a novel, flexible, flat oval coil that allows direct and repetitive magnetic stimulation of the quadriceps via the intramuscular branches of the femoral nerve. This approach produces a contraction of the muscle that is well tolerated, and we hypothesized that repetitive magnetic stimuli (rMS), given in this fashion, would induce a progressive failure of quadriceps tension generation and could thus be used as a nonvolitional test of endurance. Because of the issues of rate and recruitment noted above, we did not believe that rMS could appropriately be tested against a volitional protocol. Therefore we aimed in the present study to address three questions: first, could rMS be used practically and reproducibly as a nonvolitional method of assessing failure of quadriceps tension generation in vivo; second, could rMS distinguish the

The costs of publication of this article were defrayed in part by the payment of page charges. The article must therefore be hereby marked "advertisement" in accordance with 18 U.S.C. Section 1734 solely to indicate this fact. 
endurance properties of the quadriceps muscle of COPD patients compared with healthy age-matched controls; and third, were the endurance properties of the quadriceps muscle related to fiber-type composition and oxidative enzyme content.

\section{METHODS}

Subjects. Eight male patients with advanced COPD classified according to the GOLD criteria (26), in whom quadriceps dysfunction was likely (even though they were without significant comorbidity or evidence of exacerbation in the preceding month), and eight healthy age-matched men were studied. The Royal Brompton Hospital Research Ethics Committee approved the study, and all subjects provided written, informed consent. Anthropometric measurements, fatfree mass determined by bioelectrical impedance analysis, pulmonary function tests, and the Yale Physical Activity Survey (YPAS) were recorded in all subjects (8).

Quadriceps measurements and study protocol. Subjects were studied supine, with the knee flexed at $90^{\circ}$ over the end of the bed. The ankle of the dominant leg was placed in an inextensible strap that was connected to a transducer (Strainstall, Cowes, UK) and carrier amplifier (Minograf). The signals were recorded on a computer running LabView 4.1 software (National Instruments, Austin, TX) and sampling at $100 \mathrm{~Hz}$.

The study protocol is illustrated in Fig. 1. Before the endurance protocol was started, quadriceps strength was measured by supramaximal magnetic stimulation of the femoral nerve [quadriceps twitch force (TwQ)] and by maximal isometric voluntary contraction (QMVC) following a 20-min rest period for depotentiation. Femoral nerve stimulation was achieved unilaterally according to a previously described technique (30). We used a double Magstim 200 magnetic stimulator, discharging both units simultaneously at $100 \%$ of power output (Magstim, Whitlands, Dyfed, Wales, UK) through a 70-mm "branding iron" coil (Prototype coil, Magstim) positioned high in the femoral triangle; values reported are a mean of seven stimuli. Supramaximality with this technique has been demonstrated in previous studies $(15,32)$. The optimal coil position was outlined in indelible marker at the start of the experiment, and supramaximality was confirmed in each subject. QMVC was also performed supine, and the force generated was visible to subject and investigator for positive feedback. Repeated efforts (minimum of 3 ) were made with vigorous encouragement until there was no improvement in performance; the biggest effort recorded was used for analysis. Efforts were sustained for at least $5 \mathrm{~s}$. Subjects rested for $30 \mathrm{~s}$ between each contraction. Surface electromyographic (EMG) signals were recorded during TwQ stimulation given before and after rMS. A schematic diagram and photograph of the equipment is shown in Fig. 2.

For the endurance protocol, we used a Magstim Rapid ${ }^{2}$ magnetic nerve stimulator system with a specially designed flexible, flat oval coil $(31 \times 28 \mathrm{~cm})$ wrapped around the quadriceps muscle. The coil consisted of an elliptical shaped coil with nine concentric insulated copper rings encased in silicone. A space was left between the exterior of the insulation and the silicone to allow pumping of a cooling fluid, 3-ethoxy-1,1,1,2,3,4,4,5,5,6,6,6-dodecafluoro-2-triflouromethyl-hexane. The stimulator was set at a frequency of $30 \mathrm{~Hz}$, a duty cycle of 0.4 ( $2 \mathrm{~s}$ on, $3 \mathrm{~s}$ off), and for 50 trains ( $250 \mathrm{~s})$. The stimulator intensity was adjusted for each subject so as to initially generate $30 \%$ of their supine QMVC. Force production was measured continually during the endurance protocol. Twitch quadriceps force and QMVC were remea- sured at 10 min after rMS. Nine subjects (4 patients and 5 controls) were restudied on separate days to assess reproducibility.

$E M G$ recording. Surface recordings of the rectus femoris response to magnetic stimulation (TwQ) before and after the rMS protocol were obtained using disposable skin-taped silver electrodes (Sensi-Prema neonatal ECG electrodes, Maersk Medical, Stonehouse, UK). The EMG signals evoked by femoral nerve stimulation (termed compound muscle action potential, CMAP) in the inguinal triangle were amplified, recorded at $20 \mathrm{kHz}$, band-pass filtered between 0.3 and $3 \mathrm{kHz}$, and stored using a Synergy portable EMG machine (Synergy V4.0, Medelec, Oxford Instruments). The magnetic stimulator triggered the EMG machine, so that each stimulation elicited an EMG response that was recorded and the peak-to-peak amplitude measured. The rectus femoris activity was recorded from electrodes placed over the belly of the muscle in its long axis (37).

Quadriceps muscle biopsy. A percutaneous needle biopsy of the vastus lateralis of the contralateral (i.e., nondominant) leg to the endurance study (4) was performed in all subjects. Using standard procedures in the Maastricht laboratory (12), samples were immediately frozen in liquid nitrogen and stored at $-80^{\circ} \mathrm{C}$ until further processing. For analyses, a $5 \%$ (wt/vol) homogenate was prepared by dispersion (Polytron PT 1600 E, Kinematica, Lucerne, Switzerland) followed by 1 min sonication (Branson 2210, Branson Ultrasonics, Danbury, CT) of the tissue in SET buffer $(250 \mathrm{mM}$ sucrose, $2 \mathrm{mM}$ EDTA, $10 \mathrm{mM}$ Tris, $\mathrm{pH}$ 7.4). Samples were centrifuged (10 min, $10,000 \mathrm{~g}, 4^{\circ} \mathrm{C}$ ), and the supernatant was used for enzyme activity assays: phosphofructokinase (PFK; EC 2.7.11), 3-hydroxyacyl-CoA dehydrogenase (HAD; EC 1.1.1.35), citrate synthase (CS; EC 2.3.3.1), and glycogen phosphorylase (GlyP; EC 2.4.1.1), were analyzed spectrophotometrically (Multiskan Spectrum, Thermo Labsystems, Breda, The Netherlands). The remaining pellet was resuspended in three volumes of ice-cold extraction buffer $(100 \mathrm{mM}$ $\mathrm{Na}_{4} \mathrm{O}_{7} \mathrm{P}_{2} \cdot 10 \mathrm{H}_{2} \mathrm{O}, 5 \mathrm{mM}$ EDTA, $1 \mathrm{mM}$ DTT, $\mathrm{pH} 8.5$ ), incubated on ice for $30 \mathrm{~min}$, and centrifuged $\left(10 \mathrm{~min}, 10,000 \mathrm{~g}, 4^{\circ} \mathrm{C}\right)$. From this, the supernatant was used for myosin heavy chain (MyHC) isoform analysis. Gels were run for $22 \mathrm{~h}$ using a Protean II xi Cell Gelectrophoresis system (Bio-Rad, Veenendaal, The Netherlands) at $20 \mathrm{~mA}$ with increasing voltage to a maximum of $350 \mathrm{~V}$. Approximately 1.0 $\mu \mathrm{g}$ of protein was loaded per lane. Gels were silver-stained (Silver Stain Plus Kit, Bio-Rad), scanned, and photographed with a scanning densitometer (Fluor-S MultiImager, Bio-Rad), after which bands were quantified using Quantity One software (Bio-Rad). MyHC I, IIA, and IIX isoforms were expressed proportionally to each other.

Data collection. Quadriceps muscle endurance was calculated in three ways: by measuring peak force generated for each train both manually and from automated digital processing at predetermined time points $(10,20,30,40$, and 50 trains); by the time for the force generated by the muscle to fall to a percentage of baseline; and by integrating the force generated to calculate the force time index $(\mathrm{kg} / \mathrm{s})$.

Statistical analysis. Data are expressed as means \pm SD. Variables were compared between groups using unpaired $t$-tests. Possible correlations between quadriceps endurance and muscle biopsy results were evaluated using a Pearson correlation. A $P$ value of $<0.05$ was taken to be significant, except for the analyses of force generation at multiple time points where, since multiple end points were available, we sought $P<0.01$. A statistical software package was used for all calculations (Statview; SAS Institute; Cary, NC). Where necessary, low-frequency quadriceps fatigue was defined as a fall in the unpotentiated TwQ of $>15 \%$; this figure, which to some extent is arbitrary,
Fig. 1. Study protocol. TwQ, quadriceps twitch force measured by supramaximal femoral nerve magnetic stimulation. QMVC, quadriceps maximal isometric voluntary contraction.
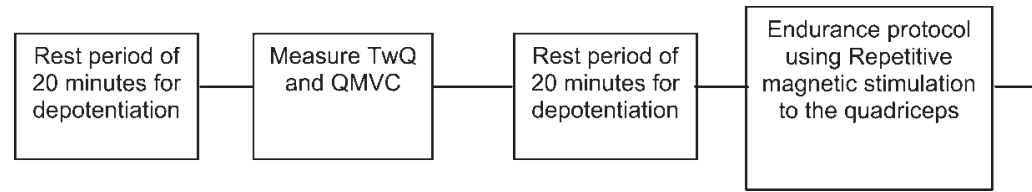

Remeasure TwQ and MVC at 10 minutes 

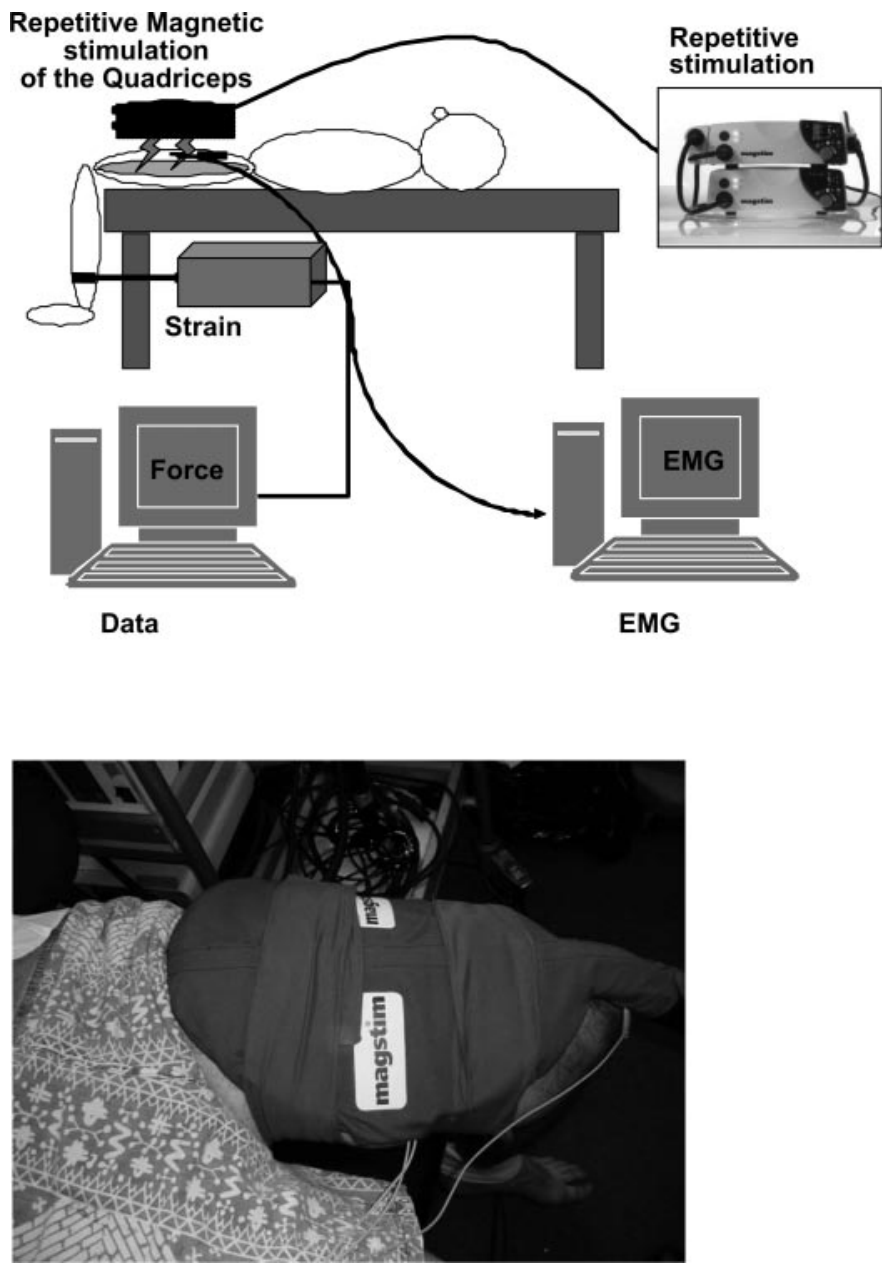

Fig. 2. Schematic diagram of equipment setup for the endurance run using repetitive magnetic stimulation, and a picture of the quadriceps coil wrapped around the muscle of a subject.

has been used by other investigators (e.g., Ref 31), although it should be noted that they have measured potentiated twitches. A BlandAltman plot was used to assess reproducibility, and the intraclass correlation coefficient was calculated separately for patients and control subjects.

\section{RESULTS}

Patient characteristics. The characteristics of the subjects are shown in Table 1 . The patient and control groups were well matched with respect to age and body composition. The patients with COPD had severe disease as defined by the GOLD criteria [mean $\pm \mathrm{SD}$ of forced expiratory volume for $1 \mathrm{~s}$ $\left(\mathrm{FEV}_{1}\right) 24.8 \pm 4.04 \%$ predicted]. Quadriceps strength measurements, when assessed using twitch force or maximal voluntary contraction force, were numerically lower in the COPD group than the control group, but the differences did not reach statistical significance.

Quadriceps force and endurance measurements. Force was continuously measured during the rMS endurance protocol. An example of a subject's force recording is shown in Fig. 3. In all subjects, there was task failure manifest by failure of the quadriceps muscle to maintain force during the rMS endurance protocol. As expected, the COPD group fatigued more rapidly
Table 1. Subject demographics

\begin{tabular}{lcc}
\hline \hline & COPD $(n=8)$ & Controls $(n=8)$ \\
\hline Age, yr & $61.0(6.3)$ & $60.0(10.9)$ \\
Height, cm & $177(4.3)$ & $177(8.5)$ \\
Weight, kg & $78.1(17.7)$ & $87.4(11.0)$ \\
BMI, kg/m & $24.9(3.8)$ \\
FFM, kg & $24.9(5.7)$ & $64.2(7.0)$ \\
FFMI, kg/m & $57.1(9.3)$ & $20.4(1.8)$ \\
FEV $_{1}$, liters & $18.2(3.0)$ & $3.27(1.12)$ \\
FEV,$\%$ predicted & $0.89^{*}(0.20)$ & $95.5(20.7)$ \\
FVC, liters & $24.8 *(4.0)$ & $4.01(0.94)$ \\
FVC, \% predicted & $3.90(0.72)$ & $92.9(13.0)$ \\
FEV 1 /FVC & $86.6(17.5)$ & $80.5(9.2)$ \\
TLCO, \% predicted & $23.2 *(6.3)$ & \\
QMVC, kg & $36.1(10.7)$ & $44.8(12.2)$ \\
QMVC/FFM, \% & $36.5(11.9)$ & $64.8(21.5)$ \\
TwQ, kg & $69.9(18.4)$ & $9.73(2.71)$ \\
\hline
\end{tabular}

Values are expressed as means (SD). COPD, chronic obstructive pulmonary disease; BMI, body mass index; FFM, fat-free mass; FFMI, FFM index, FEV 1 , forced expiratory volume in $1 \mathrm{~s}$; $\mathrm{FVC}$, forced vital capacity; $\mathrm{TL}_{\mathrm{CO}}$, carbon monoxide transfer factor; QMVC, quadriceps maximal voluntary contraction; TwQ, quadriceps twitch force. ${ }^{*} P<0.05$ compared with controls.

than the control subjects (Fig. 4). The decline in quadriceps force was significantly different between the two groups at 10 , 20,30 , and 40 trains $(P<0.01$ at each time point). The force measurements themselves were analyzed in three ways (peak force measurements manually, peak force produced from digital processing, and integrated values for each train); however, the different methods yielded similar information, and we opted to use the peak force measured manually for all further analyses as we considered this the most likely approach to be used in clinical practice.

Time for the force to fall to $70 \%$ of baseline $\left(\mathrm{T}_{70}\right)$ was shorter in the COPD group than the control group, $55.6 \pm 26.0$ vs. $121 \pm 38.7 \mathrm{~s}(P=0.0014)$ (Fig. 5). Nine subjects had two measurements of quadriceps endurance performed at least $1 \mathrm{wk}$ apart to assess reproducibility. Figure 6 shows a Bland-Altman plot of the agreement between results of the separate visits. In all subjects there was acceptable repeatability with all of the differences falling between $95 \%$ confidence intervals. The intraclass correlation coefficient $R$ for measuring $\mathrm{T}_{70}$ was 0.90 for the controls and 0.96 for the patients, indicating excellent reproducibility.

Low-frequency fatigue. TwQ was measured before and at 10 min after the endurance protocol. None of the control subjects

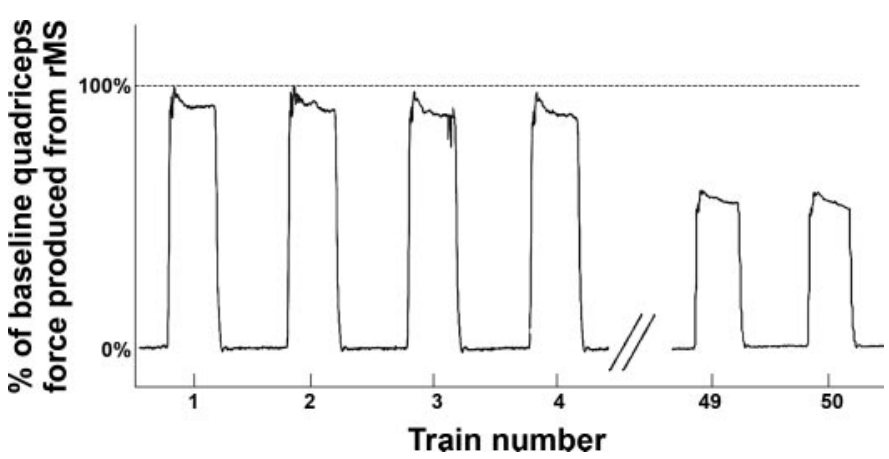

Fig. 3. An example of a subject's quadriceps force produced during repetitive magnetic stimulation (rMS) over 50 trains. The peak force was measured for each train to detect force decline. 


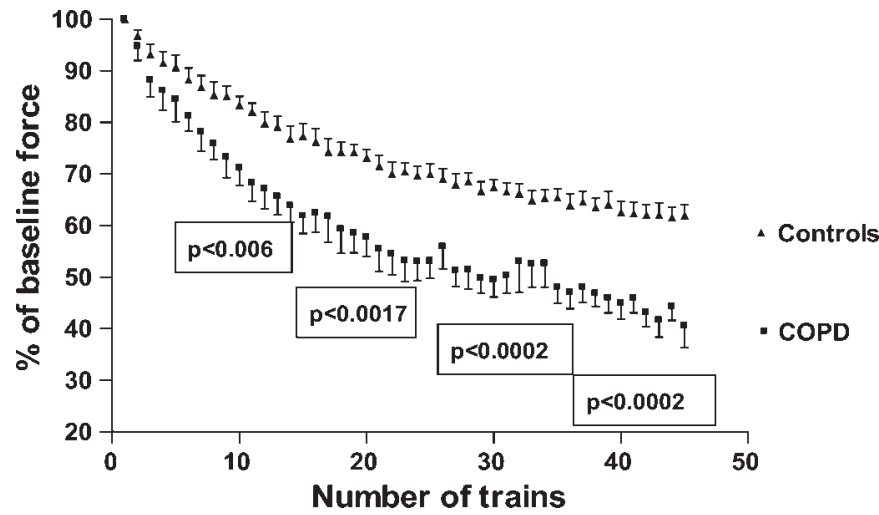

Fig. 4. Force decline during the repetitive magnetic stimulation endurance protocol. The curves were significantly different at 10,20,30, and 40 trains. COPD, chronic obstructive pulmonary disease.

but four of the eight COPD patients showed evidence of low-frequency fatigue (Table 2) using the $15 \%$ criteria. Stimuli were not accepted for this analysis if the CMAP was $>10 \%$ different from the pre-rMS values; the total number of stimuli rejected was 0 or 1 of 7 in all cases save one, where 3 of 7 were discarded. The reproducibility of the fall in TwQ is shown in Table 3; the two patients with the greatest fall ( $P 7$ and $P 8)$ on the first occasion are also the two with the greatest fall on the second occasion.

Muscle biopsy analysis. The quadriceps muscle biopsy data are displayed in Table 4. Oxidative capacity was lower in the COPD group than the controls [CS-to-PFK ratio (CS/PFK) $0.07 \pm 0.03$ vs. $0.13 \pm 0.41, P=0.007]$. There was a reduction in the expression of MyHC type I $(29.4 \pm 11.8 \%$ vs. $48.1 \pm 6.4 \%, P=0.002)$ and an increase in expression of MyHC type IIA $(54.5 \pm 12.7 \%$ vs. $38.3 \pm 6.1 \%, P=0.006)$ in the COPD group compared with controls. Positive correlations were observed between $\mathrm{T}_{70}$ and \%MyHC type $\mathrm{I}(r=$ $0.68, P=0.004)$ and between $\mathrm{T}_{70}$ and CS/PFK $(r=0.67, P=$ 0.005 ), as illustrated in Fig. 7. There was only a poor correlation noted between quadriceps strength TwQ and CS/PFK $(r=$ $0.177, P=0.512)$ and TwQ and \%MyHC type I $(r=0.279$, $P=0.296)$.

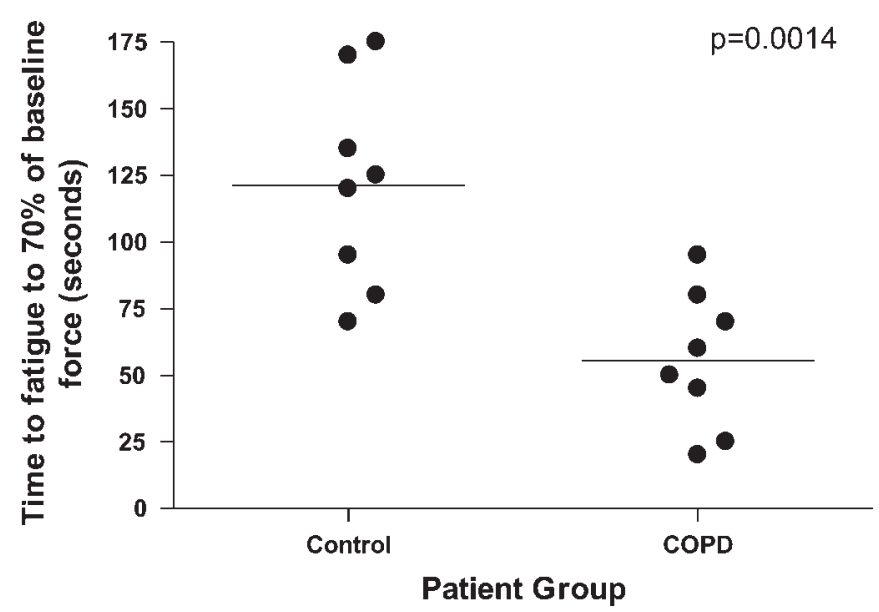

Fig. 5. Time for the force to fall to $70 \%$ of baseline $\left(\mathrm{T}_{70}\right)$ in the 2 subject groups. The mean $\mathrm{T}_{70}$ are marked with a line and are significantly different, $P=0.0014$.

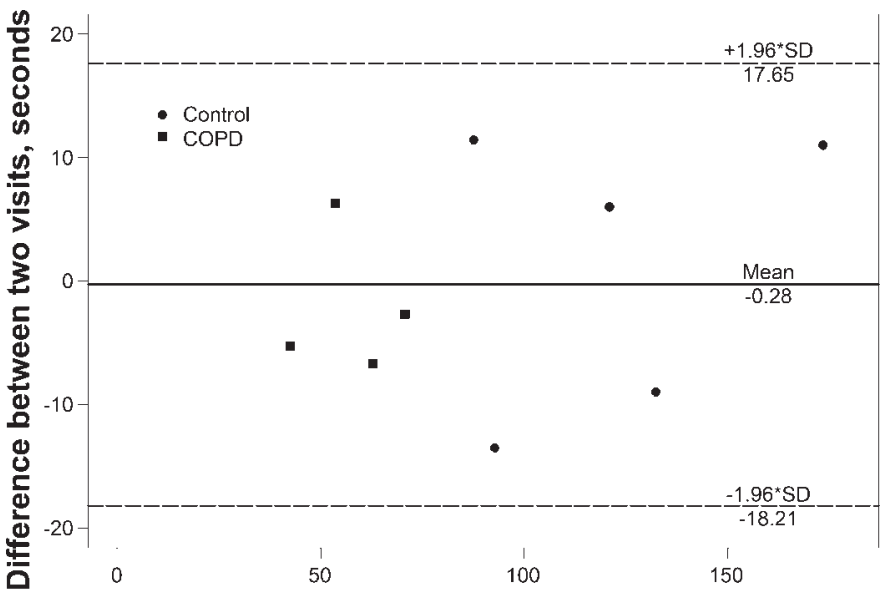

Average of two visits, seconds

Fig. 6. Bland-Altman plot displaying the agreement between results from the repeated tests in $4 \mathrm{COPD}$ patients and 5 control subjects. The mean difference between visits $(0.28 \mathrm{~s})$ is marked by the continuous line, and all subjects lie within the $95 \%$ confidence intervals (marked with the dashed lines).

Physical activity questionnaire. Patients with COPD reported reduced physical activity compared with control subjects when questionnaires were analyzed for total activity time $(11.2 \pm 7.5$ vs. $33.2 \pm 13.6 \mathrm{~h} / \mathrm{wk}, P=0.001)$ and subjects' estimated weekly energy expenditure $(2,400 \pm 1,740$ vs. $7,980 \pm 3,820 \mathrm{kcal} / \mathrm{wk}, P=0.002)$. Estimated energy expended correlated significantly with $\mathrm{FEV}_{1}(r=0.58, P=$ $0.024)$, TwQ $(r=0.57, P=0.022), \mathrm{T}_{70}(r=0.55, P=0.027)$, and with biopsy features (\%MyHC type I, $r=0.53, P=0.035$ ) considering patients and controls taken together.

\section{DISCUSSION}

The main finding of this study is that quadriceps endurance, assessed using rMS, can be safely and reproducibly measured in healthy older humans and in patients with a serious medical condition (COPD). We observed that endurance was reduced in patients with COPD compared with age-matched control subjects. The reduced endurance seen in the COPD patients was associated with a reduced proportion of type I fibers and a reduced ratio of oxidative to glycolytic enzymes, confirming the biological validity of the measurement. This technique provides a well-tolerated method to assess quadriceps endurance and therefore could be useful for future clinical studies.

Critique of method. A weakness of our study is that the cause of force loss is not clear. Evidence of low-frequency fatigue was observed in half of the COPD patients and none of the controls. Since rMS aimed to generate $30 \%$ of maximum voluntary contraction (MVC), the greatest fall in TwQ that we could have observed was 30\%, and it follows that TwQ could be a relatively insensitive test for a protocol that only stimulates a portion of the muscle; we therefore believe that lowfrequency fatigue is the most likely cause of failure of tension generation. Interestingly, in our original description of the technique (30), we applied a demanding voluntary protocol in which the entire muscle was activated. The mean fall in unpotentiated TwQ observed was $45 \%$. Had a similar protocol been applied to one-third of the muscle, we should expect the fall in TwQ to be $15 \%$, which may explain why none of the controls and only four of eight patients reached this threshold. 
Table 2. Muscle contractility before and after the rMS protocol

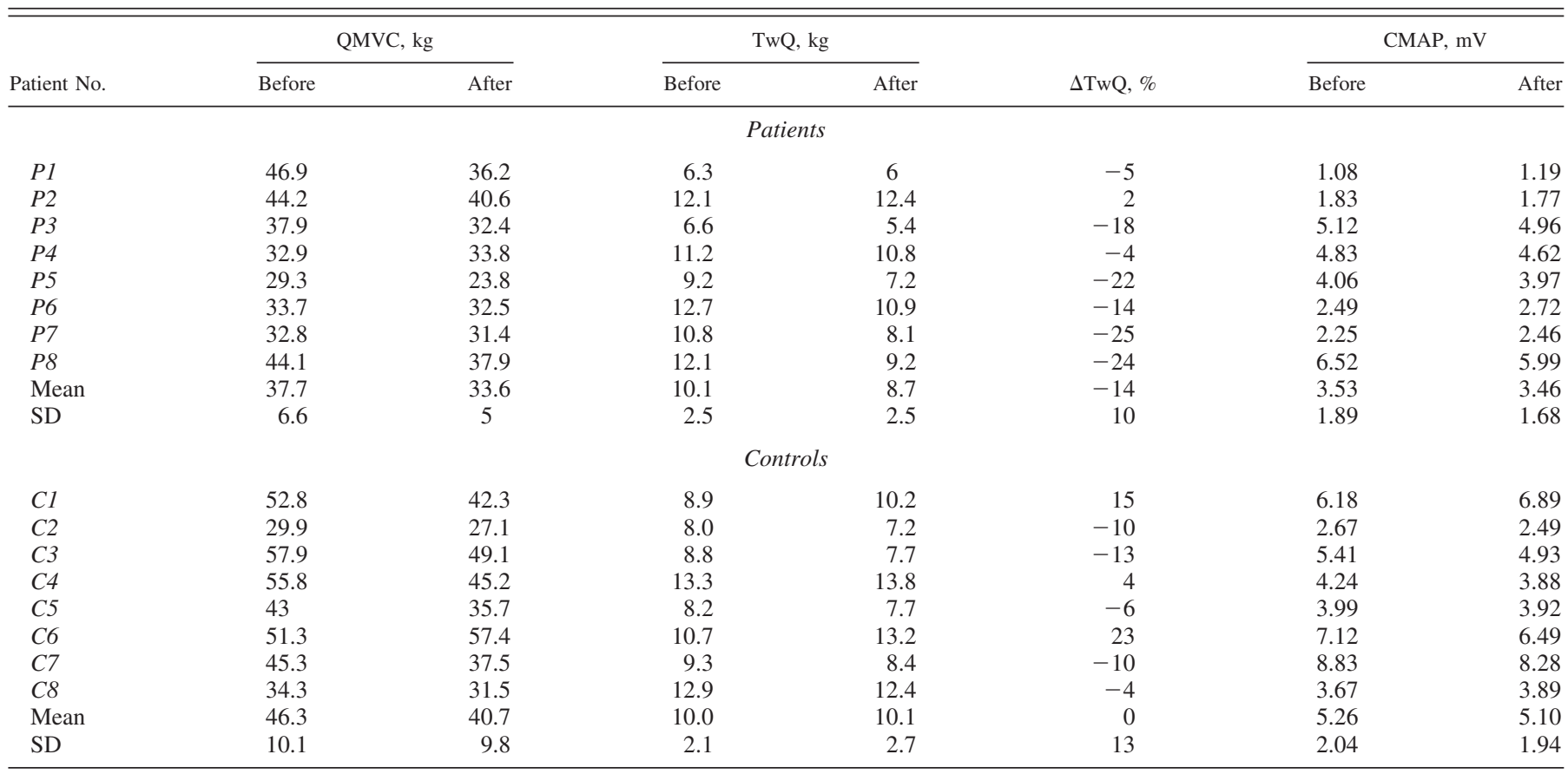

rMS, repetitive magnetic stimulation; CMAP, compound muscle action potential. $P 1-P 8$, COPD patients; $C 1-C 8$, control subjects.

Nevertheless, it proved impossible to confidently obtain CMAPs during rMS because of artefact, and therefore a contribution from high-frequency fatigue or transmission failure cannot be absolutely excluded.
In our study the difference in baseline quadriceps strength between the two groups did not reach statistical significance, most likely because of the small sample size. In a larger study by Man et al. (22), quadriceps strength measured using single

Table 3. Reproducibility of changes in TwQ after endurance protocol was performed on 2 occasions in 4 patients and 5 control subjects

\begin{tabular}{|c|c|c|c|c|c|c|c|}
\hline Patient No. & \multicolumn{3}{|c|}{ Stimuli Before Protocol } & \multicolumn{3}{|c|}{ Stimuli After Protocol } & Fall in TwQ, \% \\
\hline \multicolumn{8}{|c|}{ Patient trial 1} \\
\hline P6 & 33.7 & 12.7 & 2.49 & 32.5 & 10.90 & 2.72 & 14 \\
\hline$P 7$ & 32.8 & 10.8 & 2.25 & 31.4 & 8.08 & 2.46 & 25 \\
\hline$P 8$ & 44.1 & 12.1 & 6.52 & 37.9 & 9.18 & 5.99 & 24 \\
\hline P4 & 34.1 & 11.7 & 3.95 & 32.8 & 10.6 & 3.69 & 9 \\
\hline P6 & 28.5 & 9.12 & 3.07 & 26.4 & 9.33 & 3.13 & -2 \\
\hline P7 & 27.5 & 9.48 & 1.41 & 25.8 & 7.81 & 1.28 & 18 \\
\hline$P 8$ & 42.3 & 11.5 & 5.38 & 37.7 & 9.2 & 4.64 & 20 \\
\hline \multicolumn{8}{|c|}{ Control trial 1} \\
\hline$C 1$ & 52.8 & 8.88 & 6.18 & 42.3 & 10.20 & 6.89 & -15 \\
\hline \multicolumn{8}{|c|}{ Control trial 2} \\
\hline$C 1$ & 46.6 & 10.4 & 4.81 & 46.1 & 10.3 & 4.60 & 1 \\
\hline$C 2$ & 32.5 & 7.9 & 3.91 & 34.7 & 7.5 & 3.63 & 6 \\
\hline C3 & 49.3 & 7.9 & 4.76 & 46.3 & 7.93 & 4.41 & 0 \\
\hline C4 & 55.2 & 13.7 & 6.93 & 54.0 & 12.8 & 7.02 & 7 \\
\hline$C 8$ & 44.4 & 11.6 & 4.67 & 42.0 & 10.7 & 4.33 & 8 \\
\hline
\end{tabular}

Note that the two patients with the greatest fall in TwQ on the first trial $(P 7$ and $P 8)$ also do so on the second trial. 
Table 4. Muscle biopsy data

\begin{tabular}{lcc}
\hline \hline & COPD $(n=8)$ & Controls $(n=8)$ \\
\hline Oxidative enzymes, U/g protein & & \\
$\quad$ CS & $19.5(8.6)$ & $36.2(27.2)$ \\
$\quad$ HAD & $18.8^{*}(6.9)$ & $35.2(19.7)$ \\
Glycolytic enzymes, U/g protein & $293(157)$ & $292(221)$ \\
$\quad$ PFK & $975(521)$ & $1,030(648)$ \\
GlyP & $0.07^{*}(0.03)$ & $0.13(0.41)$ \\
CS/PFK & $0.07 *(0.03)$ & $0.15(0.07)$ \\
HAD/PFK & $29.4^{*}(11.8)$ & $48.1(6.4)$ \\
MyHC I, \% & $54.5^{*}(12.7)$ & $38.3(6.1)$ \\
MyHC IIA, \% & $16.1(7.4)$ & $13.6(8.2)$ \\
MyHC IIX, \% &
\end{tabular}

Values are expressed as means (SD). CS, citrate synthase; HAD, hydroxyacyl-CoA dehydrogenase; PFK, phosphofructokinase; GlyP, glycogen phosphorylase; CS/PFK, CS-to-PFK ratio; HAD/PFK, HAD-to-PFK ratio; MyHC I, IIA, and IIX are myosin heavy chain isoforms I, IIA, and IIX. $* P<0.05$ compared with controls.

femoral nerve magnetic stimulation was reduced in patients with COPD compared with controls with values of 7.1 (2.2) vs. 10.0 (2.7) $\mathrm{kg}$. To control for the variable strength of the subjects, the stimulation intensity was adjusted to achieve $30 \%$ of baseline QMVC so that differences in muscle mass and strength would not influence the degree of task failure. Quadriceps strength is mainly related to muscle mass $(5,11)$, but endurance, at least when previously measured using volitional protocols, is reduced in COPD patients regardless of muscle mass (1). However, we did find reduced endurance using rMS that related to the alterations in the enzyme capacity and fiber-type distribution in the quadriceps with a correlation that was superior to that observed between strength measurements and biopsy features. This indicates that rMS may be a more sensitive marker of skeletal muscle dysfunction and that this method of assessing quadriceps muscle dysfunction may be superior to strength testing for the detection of small changes in fiber-type proportion. This is in keeping with the finding of Van't Hul et al. (35) in COPD where, compared with control subjects, MVC was reduced by $20-30 \%$ whereas performance on a volitional endurance test was reduced by $70-80 \%$.
A potential critique of our study is that the patient is required to generate an MVC to calibrate the intensity of the rMS protocol. However, because in most skeletal muscles (23), including the quadriceps (30), the unpotentiated twitch tension is $\sim 20 \%$ of the MVC, the alternative, for patients unable to generate an MVC, would be to run the rMS protocol aiming to generate $150 \%$ of the unpotentiated TwQ.

The duty cycle $(0.4)$ we adopted was influenced by the approach of Burke et al. (7), who studied isolated muscle fatigue using electrical stimulation. They recorded mechanical and electrical responses in the cat gastrocnemius muscle during repeated tetanization using trains lasting $330 \mathrm{~ms}$ every second, i.e., a duty cycle of 0.33 , at a frequency of $40 \mathrm{~Hz}$ to assess muscle fatigue. They observed that the tension produced declined significantly after 30 trains. We selected a stimulation frequency of $30 \mathrm{~Hz}$ because it is representative of motor neuron firing frequencies during strong human skeletal muscle contractions; $20 \mathrm{~Hz}$ is the level at which the femoral nerve motor neurons discharge for ambulation while $40 \mathrm{~Hz}$ is analogous to sprinting (14).

Skeletal muscle fatigue is defined as a reversible loss of the capacity to generate force resulting from activity under load (3). Low-frequency fatigue results in loss of force generation in response to low stimulation frequencies $(<20 \mathrm{~Hz})$. An accepted method to detect low-frequency fatigue in clinical studies is to measure the force elicited from a single stimulus. A number of investigators have confirmed that a twitch elicited by magnetic stimulation of the femoral nerve can be used to detect fatigue $(20,30)$. It is important to note that a fall in the twitch quadriceps tension only indicates contractile fatigue as a consequence of excitation-contraction coupling if there is no documented change in the CMAP amplitude; otherwise it may be due to transmission failure.

Any measurement of muscle fatigue depends on the stimulation paradigm used, so it is difficult to compare our method of repetitive magnetic stimulation with whole body exercise or isolated quadriceps exercise. The ventilatory limitation that occurs with effort-dependent exercise can curtail endurance tests so that quadriceps muscle fatigue may not be evident at
Fig. 7. Correlations between strength and endurance properties and muscle biopsy analysis. Positive correlations were observed between $\mathrm{T}_{70}$ and percentage of myosin heavy chain type I (\% MyHC I) $(r=0.68, P=0.004)$ and between $\mathrm{T}_{70}$ and citrate synthase-to-phosphofructokinase ratio $(\mathrm{CS} / \mathrm{PFK})(r=0.67, P=$ $0.005)$. Weaker correlations were observed between TwQ and \%MyHC I $(r=0.279, P=$ $0.296)$ and between TwQ and CS/PFK $(r=$ $0.177, P=0.512$ ).
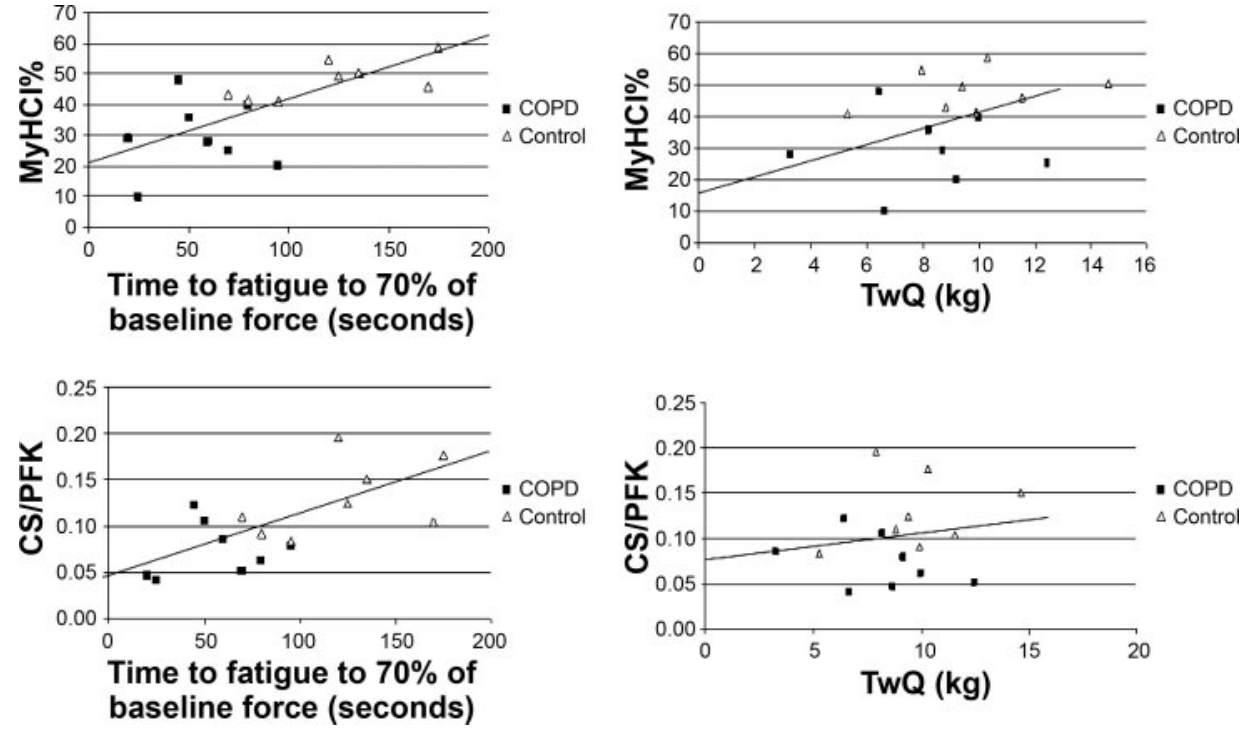

J Appl Physiol • VOL 103 • SEPTEMBER 2007 - www.jap.org 
the time of exercise termination; indeed, recent data suggest that the occurrence of quadriceps fatigue is a determinant of the cause of exercise limitation (31) and also, in part, is a determinant of the efficacy of bronchodilators (27). These problems are largely circumvented with rMS. We could have compared rMS with a volitional protocol (e.g., repeated voluntary efforts at $30 \% \mathrm{MVC}$ ), but this would not have been a fair comparison because the brain is able, by varying firing rate and recruitment, to preserve $30 \%$ force output for a considerable period of time. For example, even in a study in which normal subjects were required to sustain a 50\% maximal quadriceps effort continuously (i.e., a duty cycle of 1.0), the mean endurance time was $78 \mathrm{~s}$ (21). Therefore, in the present study we chose to compare endurance with biopsy findings.

Physiological results and muscle biopsy findings. It is well established that, when patients with advanced COPD are compared with control subjects, there is an excess of type II fibers and a reduction in oxidative enzymes $(13,17)$. Physiologically, one would expect such changes to result in reduced quadriceps endurance. Thus, at one level, our data may be considered unsurprising, but our data are, to our knowledge, the first time that a new physiological test of muscle function has been validated by comparison with biopsy data.

Significance of findings. Our method is shown to be practical in the sense that it was tolerated by patients with advanced COPD. The stimulation coil used for this study, like previous coils used in magnetic stimulation, has a tendency to heat up. In practice, if several patients need to be tested in close succession, this can be resolved by the use of fans to cool the coil or by having a second coil. In the longer term, technical advances to actively cool the coil (e.g., Ref. 25) may reduce overheating. The technique was shown to be reproducible (Fig. 6).

We describe a novel method for assessing quadriceps fatigue in patients with COPD that is acceptable to patients and that correlates with muscle biopsy data. Since this method of assessing quadriceps endurance is not subject to motivation, is reproducible, and relates to fiber-type proportions, we believe it could have particular relevance to patients in the intensive care unit or in patients unable to perform a maximal effort for neurological or other reasons. Peripheral muscle dysfunction is an important consequence of critical illness neuromuscular abnormality (18), and our technique could be used to measure it before the patient is clinically able to cooperate.

Previous work has suggested that the magnitude of quadriceps dysfunction amongst COPD patients varies depending on the severity of disease (35). We chose to study patients with severe disease, and there is a large difference in reported physical activity between such patients and normal subjects that has been confirmed elsewhere using objective measures (28). It is therefore not surprising that we have seen such a clear difference in the endurance and biopsy results. The sample size was not large enough for us to be able to draw conclusions on the relationship between lung function and quadriceps endurance; however, the results do suggest that reduced endurance is linked with other features in the quadriceps known to be associated with COPD, specifically fibertype shift and enzyme content. It is known that physical activity is reduced in COPD patients (28); however, the relationship between physical activity and quadriceps strength is modest. We found that the patients had reduced endurance judged by rMS and speculate that reduced endurance may be a contributory factor to the reduced activity displayed by COPD patients.

Endurance was significantly reduced in COPD patients. Although the relationship between fiber-type proportion and $\mathrm{T}_{70}$ was reasonably strong considering COPD patients and normal subjects together (Fig. 7), it would have been less convincing had the COPD patients been considered in isolation. We speculate that the correlation could have been closer had we studied and biopsied the same leg, but this would have been impractical in a single session. Moreover, the available data do not suggest a large role for handedness in determining fiber-type composition (19). In future studies, it will be necessary to study patients with milder quadriceps involvement to clarify the threshold at which our technique can usefully detect differences between health and disease.

In summary, this study describes a novel, effort-independent, and reproducible technique for quantifying quadriceps muscle endurance that is feasible in patients with advanced medical disease. The data confirm increased fatigability in patients with COPD. The validity of the fatigue findings with this technique are supported because reduced endurance was associated with reduced type I fibers and reduced oxidative enzymes. rMS is a sensitive in vivo method for the assessment and quantification of quadriceps endurance that is feasible in health and disease.

\section{GRANTS}

Funding for this study was from European Union ENIGMA Grant QLK6CT-2002-02285.

\section{REFERENCES}

1. Allaire J, Maltais F, Doyon JF, Noel M, LeBlanc P, Carrier G, Simard C, Jobin J. Peripheral muscle endurance and the oxidative profile of the quadriceps in patients with COPD. Thorax 59: 673-678, 2004.

2. Allen GM, Gandevia SC, McKenzie DK. Reliability of measurements of muscle strength and voluntary activation using twitch interpolation. Muscle Nerve 18: 593-600, 1995.

3. American Thoracic Society/European Respiratory Society. ATS/ERS statement on respiratory muscle testing. Am J Respir Crit Care Med 166: 518-624, 2002.

4. Bergstrom L. Muscle electrolytes in man. Determination by neutron activation analysis on needle biopsy specimens. A study on normal subjects, kidney patients, and patients with chronic diarrhea. Scand J Clin Lab Invest 68: 1-110, 1962.

5. Bernard S, LeBlanc P, Whittom F, Carrier G, Jobin J, Belleau R, Maltais F. Peripheral muscle weakness in patients with chronic obstructive pulmonary disease. Am J Respir Crit Care Med 158: 629-634, 1998.

6. Bigland-Ritchie B, Johansson R, Lippold OCJ, Smith S, Woods JJ. Changes in motoneurone firing rates during sustained maximal voluntary contractions. J Physiol 340: 335-346, 1983.

7. Burke RE, Levine DN, Tsairis P, Zajac FE 3rd. Physiological types and histochemical profiles in motor units of the cat gastrocnemius. J Physiol 234: 723-748, 1973

8. Coronell C, Orozco-Levi M, Mendez R, Ramirez-Sarmiento A, Galdiz JB, Gea J. Relevance of assessing quadriceps endurance in patients with COPD. Eur Respir J 24: 129-136, 2004.

9. Dayer MJ, Jonville S, Chatwin M, Swallow EB, Porcher R, Sharshar T, Ross ET, Hopkinson NS, Moxham J, Polkey MI. Exercise-induced depression of the diaphragm motor evoked potential is not affected by non-invasive ventilation. Respir Physiol Neurobiol 155: 243-254, 2007.

10. Fuld JP, Kilduff LP, Neder JA, Pitsiladis Y, Lean ME, Ward SA, Cotton MM. Creatine supplementation during pulmonary rehabilitation in chronic obstructive pulmonary disease. Thorax 60: 531-537, 2005.

11. Gosker HR, Lencer NH, Franssen FM, van der Vusse GJ, Wouters EF, Schols AM. Striking similarities in systemic factors contributing to decreased exercise capacity in patients with severe chronic heart failure or COPD. Chest 123: 1416-1424, 2003. 
12. Gosker HR, Schrauwen P, Broekhuizen R, Hesselink MK, MoonenKornips E, Ward KA, Franssen FM, Wouters EF, Schols AM. Exercise training restores uncoupling protein-3 content in limb muscles of patients with chronic obstructive pulmonary disease. Am J Physiol Endocrinol Metab 290: E976-E981, 2006.

13. Gosker HR, van Mameren H, van Dijk PJ, Engelen MP, van der Vusse GJ, Wouters EF, Schols AM. Skeletal muscle fibre-type shifting and metabolic profile in patients with chronic obstructive pulmonary disease. Eur Respir J 19:617-625, 2002.

14. Grimby L. Firing properties of single human motor units during locomotion. J Physiol 346: 195-202, 1984.

15. Harris ML, Polkey MI, Bath PM, Moxham J. Quadriceps muscle weakness following acute hemiplegic stroke. Clin Rehabil 15: 274-281, 2001.

16. Hulsmann M, Quittan M, Berger R, Crevenna R, Springer C, Nuhr M, Mortl D, Moser P, Pacher R. Muscle strength as a predictor of long-term survival in severe congestive heart failure. Eur J Heart Fail 6: 101-107, 2004.

17. Jakobsson P, Jorfeldt L, Brundin A. Skeletal muscle metabolites and fibre types in patients with advanced chronic obstructive pulmonary disease, with and without chronic respiratory failure. Eur Resp $J$ 3: 192-196, 1990.

18. Leitjen FSS, Harinck-de Weerd JE, Poortvliet DCJ, de Weerd AW. The role of polyneuropathy in motor convalescence after prolonged mechanical ventilation. JAMA 274: 1221-1225, 1995.

19. Lexell J, Taylor CC. A morphometrical comparison of right and left whole human vastus lateralis muscle: how to reduce sampling errors in biopsy techniques. Clin Physiol 11: 271-276, 1991.

20. Mador MJ, Deniz O, Aggarwal A, Kufel TJ. Quadriceps fatigability after single muscle exercise in patients with chronic obstructive pulmonary disease. Am J Respir Crit Care Med 168: 102-108, 2003.

21. Maisetti O, Guevel A, Legros P, Hogrel JY. Prediction of endurance capacity of quadriceps muscles in humans using surface electromyogram spectrum analysis during submaximal voluntary isometric contractions. Eur J Appl Physiol 87: 509-519, 2002.

22. Man WD, Soliman MG, Nikoletou D, Harris ML, Rafferty GF, Mustfa N, Polkey MI, Moxham J. Non-volitional assessment of skeletal muscle strength in patients with chronic obstructive pulmonary disease. Thorax 58: 665-669, 2003.

23. Mills GH, Kyroussis D, Hamnegard CH, Polkey MI, Green M, Moxham J. Bilateral magnetic stimulation of the phrenic nerves from an anterolateral approach. Am J Respir Crit Care Med 154: 1099-1105, 1996.

24. Newman AB, Kupelian V, Visser M, Simonsick EM, Goodpaster BH, Kritchevsky SB, Tylavsky FA, Rubin SM, Harris TB. Strength, but not muscle mass, is associated with mortality in the health, aging and body composition study cohort. J Gerontol A Biol Sci Med Sci 61: 72-77, 2006.

25. Nielsen JF, Klemar B, Kiilerich H. A new high frequency magnetic stimulator with an oil-cooled coil. J Clin Neurophysiol 12: 460-467, 1995.
26. Pauwels RA, Buist AS, Calverley PM, Jenkins CR, Hurd SS. Global strategy for the diagnosis, management, and prevention of chronic obstructive pulmonary disease. NHLBI/WHO global initiative for chronic obstructive lung disease (GOLD) workshop summary. Am J Respir Crit Care Med 163: 1256-1276, 2001.

27. Pepin V, Saey D, Whittom F, LeBlanc P, Maltais F. Walking versus cycling: sensitivity to bronchodilation in chronic obstructive pulmonary disease. Am J Respir Crit Care Med 172: 1517-1522, 2005.

28. Pitta F, Troosters T, Spruit MA, Probst VS, Decramer M, Gosselink R. Characteristics of physical activities in daily life in chronic obstructive pulmonary disease. Am J Respir Crit Care Med 2005.

29. Polkey MI, Kyroussis D, Hamnegard CH, Mills GH, Green M, Moxham J. Diaphragm strength in Chronic Obstructive Pulmonary Disease. Am J Respir Crit Care Med 154: 1310-1317, 1996.

30. Polkey MI, Kyroussis D, Hamnegard CH, Mills GH, Green M, Moxham J. Quadriceps strength and fatigue assessed by magnetic stimulation of the femoral nerve in man. Muscle Nerve 19: 549-555, 1996.

31. Saey D, Michaud A, Couillard A, Cote CH, Mador MJ, LeBlanc P, Jobin J, Maltais F. Contractile fatigue, muscle morphometry, and blood lactate in chronic obstructive pulmonary disease. Am J Respir Crit Care Med 171: 1109-1115, 2005.

32. Schonhofer B, Zimmermann C, Abramek P, Suchi S, Kohler D, Polkey MI. Non-invasive mechanical ventilation improves walking distance but not quadriceps strength in chronic respiratory failure. Respir Med 97: 818-824, 2003.

33. Serres I, Gautier V, Varray A, Prefaut C. Impaired skeletal muscle endurance related to physical inactivity and altered lung function in COPD patients. Chest 113: 900-905, 1998.

34. Swallow EB, Reyes D, Hopkinson NS, Man WD, Porcher R, Cetti EJ, Moore AJ, Moxham J, Polkey MI. Quadriceps strength predicts mortality in patients with moderate to severe chronic obstructive pulmonary disease. Thorax 62: 115-120, 2007.

35. Van't Hul A, Harlaar J, Gosselink R, Hollander P, Postmus P, Kwakkel G. Quadriceps muscle endurance in patients with chronic obstructive pulmonary disease. Muscle Nerve 29: 267-274, 2004.

36. Verin E, Ross E, Demoule A, Hopkinson N, Nickol A, Fauroux B, Moxham J, Similowski T, Polkey MI. Effects of exhaustive incremental treadmill exercise on diaphragm and quadriceps motor potentials evoked by transcranial magnetic stimulation. J Appl Physiol 96: 253-259, 2004.

37. Winter DA, Yack HJ. EMG profiles during normal human walking: stride-to-stride and inter-subject variability. Electroencephalogr Clin Neurophysiol 67: 402-411, 1987.

38. Zattara-Hartmann MC, Badier M, Guillot C, Tomei C, Jammes Y. Maximal force and endurance to fatigue of respiratory and skeletal muscles in chronic hypoxaemic patients: the effects of oxygen breathing. Muscle Nerve 18: 495-502, 1995. 